\title{
El "nuevo mundo" y la defensa para los emergentes
}

GuILLERMo LAFFERRIERE

\section{Resumo}

Estudo o cenário mundial do século XXI e como a política de defesa interfere na inserção dos países emergentes. Investigo o papel dos Estados Unidos após o 11 de setembro, assim como a atuação da Rússia, da China e dos "novos atores": Brasil, Índia e África do Sul.

Palavras-chave: Política de Defesa; Novos e Antigos Atores Globais; Hegemonia; Multilateralismo.

\section{GuILHERMo LAFFERRIERE}

Professor associado da Universidade John Kennedy e Secretário Acadêmico do Instituto de Ensino Superior do Exército argentino.

\section{The "new world" and the defense for the emergents}

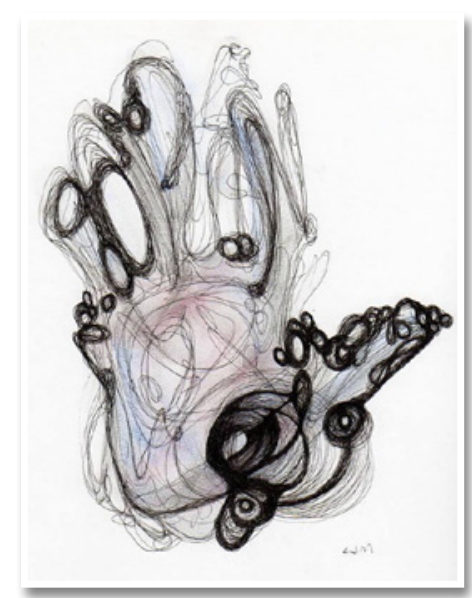

\section{Abstract}

Istudy the world scenario in XXI century and how the defense policy interferes in the insertion of the so-called "emergent countries". I investigate the role of the USA after $9 / 11$ as well the performances of Russia, China and the "new actors": Brazil, India and South Africa.

Keywords: Defense Policy; New and Old Global Actors; Hegemony; Multilateralism. 


\section{EL MUNDO QUE FUE}

\section{De la hegemonía del Nuevo Orden al reconocimiento del fin de ese sueño}

El mundo tal como se nos presenta en la ya comenzada segunda década del siglo XXI es muy diferente al que un 11 de setiembre de 2001 enfrentaba los acontecimientos por todos conocidos. En ese entonces, Estados Unidos estaban en la cúspide de lo que se puede denominar su hegemonía estratégica, como resultado de la implosión de la Unión Soviética. Washington podía enunciar a poco de producirse los ataques, la "doctrina Bush", aquella que abogaba por ataques preventivos contra todo estado que de alguna manera apoyara a los terroristas islámicos que atacaron a ese país en algunos de sus símbolos máximos de poder (WEAVER, 2012). Esa "libertad de acción" que tenía la administración Bush estaba apoyada probablemente en algunas de estas consideraciones:

- La percepción que compartían otros actores relevantes, especialmente aquellos con derecho a veto en el Consejo de Seguridad de las Naciones Unidas, que la amenaza fundamentalista islámica no era una dirigida solamente a Estados Unidos sino que estaba dirigida a ellos también. Recordemos para el caso de Rusia a las ex repúblicas soviéticas ubicadas en el Rimland donde el Islám es un factor de fuerte presencia, sin olvidar la influencia que tuvo en los sucesos en Georgia a mediados de los noventa. Y en el caso de la República Popular China, los crónicos problemas que esa nación posee con los habitantes Uighurs (CHITKARA, 1996).

- La implícita aceptación de los gobiernos de Occidente y sus aliados a lo largo del Globo que "alguna" respuesta debía darse ante los ataques, y que solamente Washington estaba en condiciones de llevar a cabo el esfuerzo que tal tarea demandaria (CHITKARA, 1996).

Los aspectos antes mencionados, creemos que fueron los que ciertamente se convirtieron en los apoyos que tuvo el ataque de Washington al gobierno Talibán de Afganistán, y en no menor 
medida, la crítica tolerancia que gozó la ya mencionada "doctrina Bush" de ataque preventivo.

Pero todo este apoyo, que iba desde una efectiva contribución en el terreno a una crítica comprensiva, se deterioró paulatinamente, en la medida que la acción de Washington, en principio enfocada en el combate al terrorismo, se diluyó con el inicio de la invasión a Iraq en el 2003. Allí, con excepción del masivo apoyo del Reino Unido, Estados Unidos complicaran decididamente su estrategia al implicarse en una campaña que a todas luces, y no hoy con los resultados a la vista, carecía de necesidad alguna en el marco de la ya mencionada guerra contra el terrorismo (LAFFERRIERE, 2003). No es objeto de este trabajo enfocarse en la larguísima campaña norteamericana en Iraq, pero si deseamos evidenciar algunos aspectos que, a nuestro particular juicio, influyeron decididamente en la configuración de la situación que si es objeto de nuestra atención. Según nuestro criterio, los mismos son los siguientes:

- La acción sobre Iraq se presentaba como necesaria sobre la base de impedir que el régimen dictatorial de Sadam Husseim hiciera uso de armas de destrucción masiva. Hubo una extendida acción político-diplomática de Washington por tratar de demostrar que esa amenaza era real, así como que existían lazos entre el gobierno iraquí con la organización Al Qaeda. La flagrante falsedad de la acusación de Estados Unidos se constituyó en un verdadero baldón para la potencia que representa en Occidente el baluarte de los conceptos de libertad y democracia. El grado de afectación a la credibilidad de Washington que esta falaz acción ha tenido también está entre los aspectos que más contribuyen al cuadro de situación actual en el que el presente trabajo intenta sumergirse (CARLISLE; BOWMAN, 2007).

- Lo mencionado en el párrafo anterior se relaciona directamente con la formulación de los objetivos a alcanzar con la campaña militar en Iraq. Esto en modo alguno es un detalle menor, ni un aspecto que puede tener interés exclusivamente desde un punto de vista teórico. El comandante militar que 
tenía como responsabilidad conquistar Iraq inició en principio la campaña para eliminar el régimen de Saddam, logrando con ello que esas presuntas armas de destrucción masiva dejaran de estar al alcance del mismo. Cuando estas se evidenciaron como inexistentes, y con la caída de Bagdad, y ya con la responsabilidad de ejercer el "control militar" del territorio iraquí, se cometió el gravísimo error de desmovilizar las fuerzas militares y policiales iraquíes, quedando bajo la responsabilidad de Estados Unidos y sus pocos aliados el control de la seguridad de la población. Esa medida alimentó el resentimiento de muchos de los desmovilizados militares y policías iraquíes, los que quedaron en una situación harto peligrosa para las fuerzas que ahora ocupaban el país, pues casi literalmente pasaron con "armas y bagajes" a sumarse a la innumerable cantidad de grupos de resistencia que surgieron en buena parte del país. Así el objetivo para las fuerzas norteamericanas volvió a cambiar, y ahora era el de luchar contra esa insurgencia, la que no solamente operaba contra sus tropas y las de los aliados, sino que simultáneamente desarrollaba una verdadera guerra civil-religiosa en el país entre las minorías suníes y chiitas que por largo tiempo convivieron en relativa paz, ante el autoritarismo del régimen de Saddam. Todo esto se llevó adelante mientras desesperadamente trataba de conformarse un gobierno iraquí que por si mismo en algún momento se hiciera cargo de la situación que creó Estados Unidos con su invasión del año 2003.

- Todo lo mencionado hizo que las tropas estadounidenses y sus aliados llevaran una larga, dura, desgastante y costosísima acción en Iraq, donde al momento de la asunción del gobierno de la actual administración Obama no presentaba una clara salida. Sin que por ello dejemos de recordar que en Afganistán la insurgencia Talibán, que se había refugiado en Pakistán luego de las acciones de Estados Unidos, volvía a operar con marcado éxito en el país del que fuera desalojada, aprovechando la falta de fuerzas de aliadas en condición de oponerse a su accionar. 
La llegada de la administración demócrata puso fin luego de un tiempo a las operaciones en Iraq y comenzó a volcar el esfuerzo a tratar de finalizar con las acciones que se llevaban a cabo simultáneamente en Afganistán. En este país, se había dado la extraña situación, en la que una exitosa campaña inicial en el 2001, por medio de Fuerzas Especiales y acciones aéreas, lograra derrocar al gobierno Talibán, poner en fuga a los militantes de Al Qaeda, pero justamente al alcanzarse el "momentum" de la misma, este se pierde con la invasión a Iraq, básicamente por la demanda que esté último escenario fue imponiendo a lo largo del tiempo en que la campaña se prolongó (WOODWARD, 2010). Esta grave falla estratégica tuvo consecuencias que hoy se perciben con claridad y afectarán el futuro de Afganistán de una manera que parecía imposible a comienzos del año 2002. Al desplazarse el esfuerzo en dirección a Iraq, Afganistán se constituyó en un escenario secundario, con relativamente escasas tropas de Estados Unidos y contingentes de la OTAN, entre los que las tropas con real capacidad de combate eran bien escasas. Completaban este complejo cuadro un gobierno en Kabul bajo la autoridad de un líder afgano poco confiable para buena parte de sus compatriotas, y una resistencia Talibán que, como mencionamos, se encontraba inicialmente refugiada en el vecino Pakistán, y que retornó rápidamente a su país a combatir por retomar el poder ni bien percibiero la incapacidad de las fuerzas norteamericanas y de la OTAN para controlar efectivamente el territorio afgano.

El gobierno de Obama comenzó a reforzar drásticamente su presencia en Afganistán, al tiempo que un esfuerzo multinacional trataba de dar institucionalidad al país y conformar una fuerza militar y de seguridad afgana en condiciones de hacerse cargo de la defensa y seguridad del país. Nuevamente, los cambiantes objetivos hicieron que fuera harto difícil establecer un "road map" que posibilitara crear una situación favorable para abandonar Afganistán. El desgaste de la campaña en Iraq, sumado a la falta de logros evidentes para el público norteamericano y europeo ha coadyuvado a que explícitamente se anunciara que a fines del 2014 la masa de las tropas aliadas abandonará Afganistán, aunque hay contingentes que expresaron que lo harán aún antes de esa 
fecha. Analistas de la talla de Ahmed Rashid han expresado que ya hay tratativas entre los aliados y los líderes del Talibán para llegar a algún compromiso post 2014, pues resulta evidente que cuanto menos ese movimiento islámico volverá a tener una presencia significativa en Afganistán, y no es de descartar que se hagan del gobierno nuevamente (RASHID, 2012).

\section{REGRESANDO AL FUTURO}

\section{De como ciertos procesos curiosamente parecen repetirse}

No adscribimos a la corriente que busca en la Historia una "repetición" de circunstancias. Pero tampoco podemos dejar de reconocer que ciertas circunstancias del pasado pueden ayudarnos a comprender mejor los hechos del presente. He ahí, al menos para nosotros, la razón del estudio de la Historia. Esto viene a cuento, porque tenemos la íntima convicción que en no poca medida esta situación que describiremos a continuación guarda semejanzas con el cuadro estratégico que se diera a mediados de los setenta con el abandono de Vietnam por parte de los Estados Unidos. También, en esos años, las fuerzas de este país y la de algunos aliados combatieron por una larga década contra un enemigo elusivo como el que ofreció resistencia en Iraq luego de lograda la derrota de las Fuerzas Armadas iraquíes y la caída del régimen. La semejanza se extiende a los distintos cambios de objetivos que la campaña tuvo, al masivo empeñamiento de fuerzas militares, a la falta de capacidad para alcanzar un objetivo factible de obtener y que el pueblo estadounidense pudiera apoyar. Asimismo, y de manera asombrosamente coincidente, los cierres de las respectivas campañas estuvieron acompañados por crisis económicas globales de gran magnitud. La denominada "Crisis del petróleo" producida en 1973, con motivo de la Guerra del Yom Kippur; y la crisis económica que tuviera su aparición en el año 2008, que también tuvo al precio del petróleo como una de sus evidencias junto a la caída de algunas de las entidades financieras más importantes del mundo.

Al promediar los años setenta, Estados Unidos iniciaron uno de sus períodos de mayor retraimiento en cuanto a su capacidad para 
desarrollar campañas militares prolongadas. Y esto era el producto natural del fracaso alcanzado en el Sudeste Asiático, el cual llevó a un replanteo profundo de la estrategia militar de Washington. En ese entonces, a diferencia de nuestros días, la Unión Soviética seguía siendo una real amenaza a Occidente, y arriesgamos a pensar que la supremacía estratégica nuclear de Estados Unidos se constituyó en la real barrera de contención a los soviéticos. Su Ejército estaba profundamente desgastado y desmoralizado por la larga e infructuosa lucha llevada a cabo en el Sudeste de Asia. Se requerirían varios años y una profunda restructuración del sistema militar de Norteamérica, hasta que ese país estuviera nuevamente en condiciones de operar allende sus fronteras de una manera eficiente, tal como se demostró en la primera Guerra del Golfo en 1991 (KITFIELD, 1997).

Hoy, Estados Unidos, sus Fuerzas Armadas, y especialmente sus tropas del Ejército y de la Infantería de Marina atraviesan una nueva etapa de introspección y decantación de la experiencia que el prolongado despliegue de esta década les ha causado. Hay en ellos un profundo debate, en el cual entre otros aspectos se discuten los siguientes:

- Ha existido un acento colocado en las operaciones de contrainsurgencia, las que en un primer análisis aparecen como razonables dada la característica del enemigo que se enfrentó en Afganistán, en una etapa posterior en Iraq luego de su conquista, y nuevamente en Afganistán con la renovada intención de reforzar las operaciones en ese país. Pero un análisis más profundo es el que preocupa en Estados Unidos pues en razón que las tropas empeñadas en Afganistán y en Iraq siempre fueron voluntarias, a diferencia de Vietnam, la exigencia de la prolongada campaña obligó a que tropas no concebidas para desarrollar acciones contrainsurgentes directas fueran reconvertidas a través del entrenamiento para desarrollar esas tareas. Así tropas de Artillería de Campaña, Antiaérea, de Ingenieros, y otras perdieron su aptitud para desarrollar las acciones para las que fueron organizadas, y hay hoy una discusión sobre el nivel de afectación que todo ello produjo en la capacidad 
estadounidense para desarrollar operaciones militares en un nivel de exigencia militar superior.

- Los analistas militares en Estados Unidos avizoran escenarios a futuro donde por un tiempo no habrá despliegues masivos de tropas. Asimismo, se discute el nivel de capacitación contrainsurgente que habrá que mantenerse y cual será la necesidad de recuperar capacidad convencional hacia el futuro. Una prueba de esto es el "regreso" a la doctrina anfibia que el Cuerpo de Marines viene retomando desde hace poco tiempo, en el convencimiento que los prolongados despliegues contrainsurgentes de estos años han afectado negativamente las que se asume como la razón de ser de esa Fuerza Armada: penetrar, desde una "base" en el mar, un territorio enemigo, apelando a la capacidad de proyectar poder desde el aire y en menor medida desde embarcaciones de desembarco en la costa. Piénsese que durante el prolongado empeñamiento en Afganistán y en Irak, este Cuerpo de Marines sirvió más como una suerte de "ejército duplicado" del propio Ejército de Estados Unidos, haciendo difícil comprender la necesidad de dos fuerzas que hicieran en la práctica el mismo trabajo en el campo de combate (FREEMAN, 2013).

- Asimismo, se observa en los analistas militares y civiles de Estados Unidos que si bien no existe como en los setenta una "URSS" capaz de desarrollar operaciones militares en la totalidad del espectro posible para las mismas, si siguen con atención el progresivo crecimiento militar de China en el AsiaPacífico, junto con la incipiente, aunque más lenta, recuperación de la capacidad estratégica de Rusia para actuar globalmente en un futuro. Todo esto se suma a la presencia de grupos terroristas islámicos, que adscriben a esa verdadera "franquicia" que resulta ser Al Qaeda, con presencia en los países donde trató de erradicarla, en la península Arábica, especialmente en Yemen, y en Africa, donde el apoyo de Al Qaeda a los Tuaregs en Malí es una prueba evidente del poder de la organización para hacerse presente en distintos escenarios. Se suma a esto lo que pueda llegar a configurarse en el mundo árabe envuelto 
todavía en una "Primavera" que presenta diversidad de escenarios y pronósticos, y donde el caso de la guerra civil que hoy observamos en Siria aparece con rasgos similares a la que se daba en el Líbano de mediados de los setenta. En ambas ocasiones, Estados Unidos no tuvieron la capacidad de influir militarmente de manera masiva para favorecer a uno de los bandos, siempre como consecuencia de su prolongado empeñamiento anterior; en el Sudeste de Asia para el caso del Líbano y las acciones en Afganistán e Iraq en nuestros días.

- Finalmente, estos analistas no dejan de tener muy en cuenta la cuestión que la proliferación nuclear presenta en el siglo XXI. Muy a pesar de la proclamada política de evitar la misma, el hecho es que cada vez pareciera que el acceso a armamento nuclear se hace más una decisión al alcance de los más diversos estados, y más inquietante, de grupos radicalizados. Al respecto el recuerdo de los intentos realizados por el grupo Terik-e-Taliban en Pakistán en instalaciones donde se guardan armas nucleares es de por si una clara indicación que esto puede convertirse en una realidad en algún momento (NUCLEAR profusión, 2012). Además, no podemos dejar de mencionar, COmo una prueba de la vigencia de la amenaza nuclear, la situación que, al momento de escribirse este trabajo, se da en la península de Corea, donde el régimen norcoreano ha amenazado efectuar el lanzamiento de armas nucleares contra objetivos de Estados Unidos, tanto los que se encuentran en la península coreana, como los acantonados en Japón y la isla de Guam, extendiendo incluso la amenaza al propio territorio continental norteamericano. ${ }^{1}$

En concreto, Estados Unidos han dejado, según nuestra visión, de constituirse en el hegemon todopoderoso, capaz de imponer por si mismo agendas en el mundo actual. Esto abre un escenario nuevo, donde hay una oportunidad para que el preconizado multilateralismo alcance un realista grado de concreción. Además

1 Se sugiere la lectura del trabajo de Therese Delpech (2012) para obtener una mirada amplia sobre el desafío que el armamento nuclear podría imponer en el siglo XXI. 
y a favor de ese enunciado multilateralismo, coincide también que Europa está inmersa en resolver su propia crisis económica, donde el Reino Unido y Francia, si bien retienen capacidades relevantes en términos político-diplomáticos y aún militares (recordemos en el caso de éste último país su rápido despliegue en Malí liderando una coalición de naciones africanas para contraponerse al accionar de Al Qaeda y nativos Tuareg en el noroeste de ese país africano), distan de contar con poblaciones muy entusiastas en los asuntos internacionales, al menos por el tiempo que les insuma lograr una recuperación económica que asegure a sus poblaciones un nivel de vida mejor.

Esa oportunidad estratégica puede ser aprovechada por actores emergentes que hoy están ocupando, a diferencia de los setenta, espacios críticos en los campos económico-financieros, y que al observar este cuadro de situación sucintamente descripto, desarrollan acciones para actuar globalmente de una manera más notoria, aunque sin que resulte la misma, al menos con los elementos hoy a disposición, manifiestamente agresiva. Entre esos actores, hay países "nuevos" como Brasil, la India o Sudáfrica; y otros "viejos" actores, que tuvieron en los setenta y antes también relevancia estratégica por su capacidad militar relativa, y que hoy agregan a la misma una creciente influencia económica. Entre el segundo grupo de países encontramos el caso de Rusia, pero principalmente de China, que es hoy un jugador global económico de primer orden, que tiene un poder militar relativamente menor pero en constante crecimiento.

\section{LA DEFENSA DE LOS NUEVOS JUGADORES}

\section{El hard power en busca de su lugar en el siglo XXI}

Al menos mientras los países existan sobre la superficie del paneta, hay una constante que está presente más allá de las consideraciones que desde una postura idealista pudiera hacerse. Pareciera que el desarrollo económico lleva de una manera casi paralela uno similar en el campo de la defensa. Y esto es particularmente manifiesto en aquellas naciones que conciben que su desarrollo depende, de manera cada vez más relevante, de 
acontecimientos, materias primas o de aliados que están mucho más allá del horizonte que la geografía política impone en los mapas. Esta es la realidad que sirve de marco a los jugadores que mencionamos anteriormente, pero difieren muchos las circunstancias particulares de cada uno de ellos. Groseramente, podemos comenzar mencionando que salvo el caso de Brasil, los demás tienen armamento nuclear o habiéndolo potencialmente poseído han renunciado hoy al mismo como es el caso de Sudáfrica (STEYN; Van LOGGERENBERG; Van Der WALT, 2005). Es claro también que las regiones en las que cada uno de ellos hoy por hoy actúa preferencialmente presentan realidades diferentes; descontando que Brasil tecnológicamente no está alejado de adquirir esa capacidad de considerarlo necesario; y que su plan de reformulación de su capacidad militar lo estará dotando de algunos sistemas como para que esas armas puedan, llegado el caso, contar con plataformas para las mismas. ${ }^{2}$

Pero más allá de ello hay otras características que debemos tener en cuenta. Rusia, como el núcleo medular de la URSS, contaba con la capacidad de desarrollar operaciones en la casi totalidad del espectro militar, es decir, desde una guerra de baja intensidad, pasando por una con un empleo simultáneo de medios convencionales y nucleares o bien una donde se llevara adelante un intercambio de misiles estratégicos nucleares en casi cualquier parte del globo. La implosión de la URSS llevó a una enorme perdida de esa capacidad, y hoy Rusia retiene una capacidad militar que es más una sombra de la que tenía la URSS a principios de los ochenta. Sin embargo, una profunda revisión está en marcha, acompañada de un moderado crecimiento económico mantenido en estos años, de la mano del alza en el precio del gas que esa nación vende principalmente a los países de Europa Occidental. Esto ha hecho que Rusia se vuelva a mostrar con aspiraciones no ya de carácter global, pero si en el ámbito de su región, sin que haya

2 Para una perspectiva de la relación de Brasil en la región, especialmente con el Mercosur en materia de defensa, ver Mathias y Braga Matijascic (2011). 
perdido la característica de ser un enorme estado euro-asiático, el que ya Mackinder analizara en su célebre trabajo de $1904 .^{3}$

China es un caso diferente. ${ }^{4}$ Su poder estuvo basado, a nuestro critério, más en la decisión política de su líder Mao de recurrir a sus masas como arma que a un eficiente complejo militar apto para desarrollar operaciones de gran complejidad. Sin embargo, sus tropas, sobriamente equipadas, se condujeron bien durante la Guerra de Corea contra las fuerzas de las Naciones Unidas, así como contra las tropas de la India en 1962. Conocieron otras circunstancias también, y como los Estados Unidos sufrieron una severa derrota en 1979 cuando llevaron adelante una ofensiva punitiva contra Vietnam, donde las fuerzas veteranas vietnamitas se impusieron con un impecable aprovechamiento de las ventajas que le daban el profundo conocimiento del terreno y la larga experiencia de combatir contra fuerzas superiores por décadas.

Hoy China está llevando adelante un esfuerzo importante especialmente para una rama de su fuerza militar que tuvo una tendencia a ser menospreciada. Nos referimos a la Armada del Ejército Popular de Liberación. Este servicio tenía las características de una marina costera, es decir, incapaz de desarrollar operaciones mucho más allá de sus bases de operaciones, y por lo tanto irrelevante para una nación que pretende tener un rol preponderante más allá de su propia geografía. Eso se viene revirtiendo, y los indicios no son menores. Sus buques sirven en la región del Cuerno de Africa combatiendo la piratería, operando con una relación "no formal" con los buques de países europeos, Estados Unidos, India, Pakistán y Rusia. Una flotilla de buques chinos ingresaron recientemente por el Mediterraneo, atravesaron el Bosforo y iialcanzaron el Mar de Mármara!! (COLE, 2012). Además, luego de un largo proceso, han comisionado su primer portaviones. Pasarán varios años antes de que obtengan la capacidad de operar el mismo de manera eficiente, y más todavía para que no sea este el único.

3 Es interesante la perspectiva que proporciona Oliker (2012).

4 Para una perspectiva única de un profundo conocedor de China, así como privilegiado testigo del proceso que hoy vive ese país, remitimos a Kissinger (2011). 
Pero el mensaje es claro: China hará de su presencia en el mar un aspecto clave de su camino para convertirse en un actor global, asegurando con su Armada las líneas de comunicaciones de las materias primas que con avidez requiere para continuar con su desarrollo.

Simultáneamente, acompaña ese progreso en la modernización y crecimiento de sus medios navales, con una presencia relevante en el Océano Indico, construyendo instalaciones navales en países como Pakistán, Sri Lanka, Birmania, al tiempo que desarrolla en su litoral costero capacidades militares para atacar mediante misiles o aviación cualquier flota que intente amenazar su litoral, principalmente en el sector más próximo a Taiwan. El otro campo donde China se muestra activa es el de la capacidad misilistica. Aquí sus desarrollos son muy relevantes, contando con una cada vez más sofisticada capacidad estratégica para lanzar armamento nuclear, así como para atacar blancos situados en el espacio exterior. Su exitosa prueba lanzando un misil que destruyó un satélite fuera de servicio en la orbita de la Tierra es una muestra elocuente de lo que mencionamos.

Finalmente el ciberespacio es otro campo donde la defensa china se muestra particularmente activa. Es más que probable que bajo control de un comando específicamente militar operen un conjunto de organizaciones distribuidas en el territorio continental, desde donde se han lanzado "ataques" cibernéticos a nivel global. Los blancos han sido comandos militares, organizaciones gubernamentales y financieras. La afectación ha sido de diverso nivel, pero es una muestra evidente que China procura alcanzar una capacidad en este campo que le permita equilibrar sus debilidades cualitativas en otros aspectos de su poder militar, especialmente en una parte importante de su Ejército, que carece de un equipamiento individual comparable al que puede observarse en las naciones más adelantadas de Occidente (FISHER, 2008).

India es otro país que ha comenzado desde 1988 un lento pero constante progreso en la inserción del país en el mercado global, constituyéndose en un verdadero fenómeno para los mercados económico-financieros del mundo. Esto ha producido un desarrollo importante, aunque cabe mencionar que el campo de la 
defensa siempre estuvo dentro de la mirada de sus líderes, toda vez que desde su independencia mantuvo guerras con Pakistán en 1947/48, 1965, 1971 y prolongadas acciones de diversa entidad con ese país en distintas oportunidades, destacando las acciones en Kargil de 1999, donde hubo oportunidad que se produjera un intercambio nuclear entre ambos países. Esta capacidad nuclear la adquirió la India en 1974, oportunidad en que realizó su primera serie de detonaciones en el desierto de Rajastan, a cerca de $80 \mathrm{~km}$ de territorio pakistaní (LAFFERRIERE, 2012). Esto se hizo al tiempo que los líderes civiles mantuvieron siempre un estricto control de los militares, razón por la cual han mantenido una continuidad institucional desde el inicio de su vida independiente.

La Armada India, al igual que su contraparte de la República Popular China, ha iniciado un proceso de modernización, que la lleva en el camino de constituirse en una herramienta de proyección del poder de la India en el Océano Indico. Tiene la ventaja comparativa de contar con una veterana fuerza aeronaval embarcada, con experiencia de combate,${ }^{5}$ así como el empleo de submarinos convencionales y nucleares, estos últimos rentados a Rusia, aunque en proceso de construir sus propios desarrollos (LUTHRA, 2012). La Armada India es hoy una de las fuerzas navales con mayor expansión en el mundo.

Sudáfrica, por su parte, ha sido un país que ha contado desde siempre con Fuerzas Armadas con una amplia experiencia operacional. Como parte del Commonwealth participó con distinción en la Primera y Segunda Guerra Mundiales, donde sus tropas se destacaron por su resistencia ante la adversidad y el espíritu combativo. Durante buena parte de las décadas de los setenta y los ochenta, sus tropas participaron en operaciones en la guerra de independencia angoleña y antes lo hicieron también en la vecina Namibia (BECKETT, 1985). Con la caída del régimen de apartheid, las Fuerzas Armadas iniciaron un proceso de integración racial

5 Durante la guerra de 1971 con Pakistán, el entonces único portaviones de la Armada India, el INS Vikrant, lanzó más de cuatrocientas salidas aéreas contra el puerto de Chittagong y otros puertos rivereños de Pakistán Oriental. Ver Barua (2005). 
muy profundo, aunque sin perder de vista la necesidad de mantener un alto nivel de adiestramiento. Hoy en día, las tropas sudafricanas pueden considerarse las más profesionales del continente, y están inmersas también en un profundo plan de modernización y mejoramiento de sus capacidades operativas (SOUTH AFRICA'S GOVERNMENT, 2012).

Cabe que hagamos mención a Brasil. Sus Fuerzas Armadas desde el regreso a la vida institucional del país han iniciado un proceso que tuvo en la modernización de las mismas una etapa importante, pero se advierte que están ingresando a una etapa superadora para tratar de alcanzar fuerzas capaces de enfrentar los desafíos que les impone la Amazonia "Verde" y la Amazonia "Azul", tan rica en recursos energéticos para Brasil. Este proceso de modernización implica varias cosas simultáneamente:

- El mejoramiento del actual sistema de control de la Amazonia, permitiendo un mejor control de la extensa frontera continental del país y la zona costera del mismo.

- La reformulación del instrumento militar terrestre, con la adquisición de nuevos sistemas de armas y una fuerte impronta en el empleo de simuladores de última generación para el entrenamiento tanto individual como colectivo, reduciendo costos de adiestramiento y facilitando la adquisición de conocimientos a un mayor número de sus tropas, tanto individual como colectivamente.

- La adquisición de una potente fuerza submarina, que incluye un sistema a propulsión nuclear así como avanzar en la modernización y acrecentamiento de la flota, para asegurar el control en la Amazonia Azul. Esto hará que Brasil se constituya en la potencia que ejerza el control del Atlántico Sur y pueda asimismo proyectarse en algún tiempo sobre la Antártida.

- La renovación de la aviación de caza, junto con un especial acento en todo lo relativo al acceso y empleo del espacio exterior para la defensa. Esto lo hace al tiempo que desarrolla su propia versión de un avión de transporte militar que estará llamado a ser el relevo natural del sistema Hércules C-130, 
asegurándose no solamente capacidad para proyectar fuerzas en su inmenso territorio sino allende sus fronteras si fuere necesario.

- La decidida incursión en todos los aspectos relacionados con la "guerra cibernética", cuestión esta última que es de creciente interés de aquellos países que amplían los criterios de las amenazas posibles de afectar a sus estructuras vitales estatales y privadas. ${ }^{6}$ Esta capacidad evidencia de parte de la Defensa brasileña una profunda comprensión de las complejas dimensiones que la guerra puede tomar en el siglo XXI de la mano del acelerado desarrollo de la informática y lo crítico que resultará dominar estas aptitudes para preservar la propia soberanía en situaciones conflictivas.

Ahora bien, ¿Cuál es la razón por la que estos actores globales emergentes buscan contar con capacidades de Defensa tan relevantes en este siglo XXI? Consideramos que buena parte de la respuesta se encuentra en lo que venimos expresando desde el inicio del trabajo. Los países centrales no tendrán predisposición a atender con tropas en el terreno cuestiones que pudieran surgir en distintos escenarios del planeta. Y esto probablemente dará pie para que en distintas regiones del globo haya ciertos actores, probablemente los que venimos mencionando, que a través de su capacidad de Defensa tratarán de influenciar en las mismas. Esta influencia podrá tener características más o menos asociativas, en la medida que los intereses en juego así lo permitan, o bien podrán ser más duras; y en esto no necesariamente llegando al empleo directo de la fuerza, si es que cierto nivel de coerción fuese necesario.

Asimismo, asistiremos seguramente a un concepto de "región" que podrá verse ampliado por el de "regiones de interés". Es decir, zonas amplias o focales situadas fuera de la tradicional esfera de influencia, donde de alguna manera esté en juego el acceso a recursos o bien las circunstancias hagan necesario una intervención humanitaria de cierta envergadura. Nos referimos a

6 Para una perspectiva crítica de este tema, se sugiere leer Bertonha (2010). 
aquellas que tradicionalmente estaban reservadas a coaliciones ad hoc de los países centrales o de la ONU. Muy probablemente, con el amparo de esta última organización o de otras asociaciones regionales, los países que mencionamos se hagan presentes para llevar adelante tareas que antes se esperaba llevaran adelante per se o coaligadamente las denominadas potencias centrales. Consideramos que, cuando ello suceda, estaremos ante la evidencia de la concreción de lo que nos atrevemos a denominar como "multilateralidad posible". Una multilateralidad que no tendrá las características de la participación masiva de las naciones, porque la historia indica que no todas tienen aspiraciones de realmente asumir papeles preponderantes en las cuestiones globales. Y esto porque en términos políticos es relativamente sencillo pregonar por el multilateralismo, pero es harto difícil llevarlo a la práctica cuando los medios diplomáticos se muestran incapaces de solucionar situaciones que no pueden prolongarse en el tiempo.

Cuando tales circunstancias aparecen, solamente los actores con capacidad de proyectar poder militar son los que tienen las herramientas para, por ejemplo, hacer llegar la ayuda humanitaria, detener conflictos que desborden los límites de lo que la humanidad acepta en cada época, imponiendo por la fuerza la paz; o bien mediante su presencia militar coadyuvar a que una solución pacífica encuentre su camino de concreción. Todo el resto del respaldo político podrá ser relevante en determinados ámbitos, fundamentalmente de públicos internos, pero poco efectivo en los hechos, al carecer del brazo militar que concreta en el terreno las aspiraciones discutidas por los políticos. La dimensión de lo militar, en modo alguno, estará ausente en el siglo XXI, fundamentalmente para aquellas naciones que pretendan tener relevancia global.

\section{CONCLUSIONES}

El mundo que veremos en los próximos años será uno donde interactuarán de manera simultánea problemas que siempre estuvieron presentes, como son: incrementar el nivel de desarrollo de la propia población (Educación, Salud, Vivienda, Derechos Sociales); acceder a materias primas teniendo asegurado su arribo desde donde estas se originen; la necesidad de mercados para los 
bienes y servicios que se producen y que los mismos puedan arribar a destino de manera segura; la preservación de los intereses nacionales frente a los que otros actores por distintas maneras puedan oponerse. Y, además, la problemática que imponen aspectos como: el impacto de la actividad humana sobre el planeta; la proliferación de armas de destrucción masiva; la presencia extendida en distintas partes del planeta de grupos radicalizados religiosos en la búsqueda de alcanzar objetivos que difícilmente pueden ser comprendidos desde nuestra concepción laica y mundana de las cosas; los efectos no deseados de la globalización económi$\mathrm{ca}$, que tiene en la volatilidad de los mercados financieros a un actor entre inmanente y casi impersonal, en condiciones de desafiar severamente al estado nación en su capacidad de decisión en aspectos antes considerados propios de la vida interna de las naciones; y la aparición de "estados fallidos" que por su propia naturaleza se constituyan en elementos perturbadores de la paz y seguridad regional o global.

Ese escenario, complejo, contradictorio y en constante mutación, es al mismo tiempo un escenario que por lo expresado en este trabajo presenta oportunidades inimaginables durante décadas, cuando solamente se podía pensar al mundo desde una visión entre europeísta y atlantista. Es un mundo donde actores con decisión y voluntad de acción global podrán en la medida que actúen con criterios de equilibrio y cierta audacia alcanzar estadios de desarrollo nacional cada vez más importantes; pero, simultáneamente, con capacidad diplomática, económica y militar para influir en los asuntos globales en una manera inédita. De concretarse esta situación, insistimos que daremos un paso concreto para diseminar de una manera más equilibrada el ejercicio del poder en el mundo, lo que se materializará posiblemente en una ampliación de los miembros permanentes del Consejo de Seguridad. Esto último en no poca medida reflejará la caducidad del sistema que naciera con la victoria Aliada en 1945 contra la barbarie nazi, pero que desde hace décadas reclama de un ajuste. Estos nuevos actores globales, seguramente, serán parte de ello, y en no poca medida, su desarrollo del campo militar será una herramienta importante, no la única, en el logro de alcanzar esa meta. 


\section{REFERÊNCIAS}

BARUA, P. The State at War in South Asia. Lincoln: University of Nebraska Press, 2005.

BECKETT, I. Armed Forces and modern counterinsurgency. Kent: Providence House 1985.

BERTONHA, J. "Brazil: an emerging military power?" Revista Brasileira de Política Internacional, v. 53, n. 2, p. 107-124, 2010.

CARLISLE, R. P.; BOWMAN, J. S. Iraq War. New York: Facts On File, 2007.

CHITKARA, M. G. Nuclear Pakistan. New Delhi: A.P.H. Publishing Corporation, 1996.

COLE, J. China's Navy in the Mediterranean? The Diplomat, 30 jul. 2012. Disponible en: <www.thediplomat.com/flashpointsblog/2012/07/30/whys-chinas-navy-in-the-mediterranen/>. Consultado en: 1 dic. 2012.

DELPECH, T. Nuclear deterrence in the 21 st century: lessons from the cold war for a new era of strategic piracy. Santa Monica: Rand Corporation, 2012.

FISHER, R. China's military modernization: building for regional and global reach. Westport: Greenwood Publishing Group, 2008.

FREEMAN, L. Can the Marines survive. Foreign Policy, Washington, 26 mar. 2013. Disponible en: <www.foreignpolicy. com/articles/2013/03/26/can_the_marines_ survive>. Consultado en: 5 abr. 2013.

KISSINGER, H. On China. New York: The Penguin Press, 2011.

KITFIELD, J. Prodigal Soldier: How the generation of Officers born of Vietnam revolutionized the American style of war. Virginia: Brassey's Paperback, 1997.

\section{LAFFERRIERE, G. Ensayos militares de la Guerra del Golfo} Pérsico del año 2003. Buenos Aires: Nueva Mayoría, 2003.

LAFFERRIERE, G. La relación ambigua del gobierno de Pakistán respecto a grupos insurgentes talibán en territorio pakistaní (20082010). In: CONGRESO DE RELACIONES INTERNACIONALES, 
6., 2012, La Plata. Anais... La Plata: Instituto de Relaciones Internacionales de la Universidad Nacional de La Plata, 2012. Disponível em: <www.iri.edu.ar/VI_congreso/ponencias/ LAFERRIERE,\%20Guillermo_la\%20relacion\%20ambigua\%20 del\%20gobierno\%20de\%20Pakistan.pdf>. Consultado en: 1 dez. 2012.

LUTHRA, G. Indian Navy in fast forward mode. India Strategic, 2012. Disponible en: <www.indiastrategic.in/topstories1543_ Indian_Navy_in_fast_forward_mode.htm>. Consultado en: 1 dic. 2012.

MATHIAS, S.; BRAGA MATIJASCIC, V. Defesa no MERCOSUL: avanços para a integração. Tensões Mundiais, v. 7, n. 12, p. 223242, 2011.

NUCLEAR profusion. The Economist, 25 ago. 2012. Disponible en: <http://www.economist.com/node/21560877>. Consultado en: 10 nov. 2012.

OLIKER, O. Russian nuclear exercises Putin's misguided priorities. Disponible en: <www.rand.org/ commentary/2012/10/31/RAND3.html>. Consultado en: 1 dic. 2012.

RASHID, A. Pakistan on the brink: the future of America, Pakistan and Afghanistan. New York: Penguin Group, 2012.

STEYN, H.; Van LOGGERENBERG, J.; Van Der WALT, R. Armament and disarmament: South Africa's nuclear experience. Lincoln: iUniverse, 2005.

SOUTH AFRICA'S GOVERNMENT. South African Defence Review 2012 . Pretoria: Minister of Defence and Military Veterans, 2012.

WEAVER, C. P. The Bush doctrine and the tactic of preemption: understanding the concept, criticism, and implications for National Policy and International Law. Virginia: Robertson School of Government, Regent University, 2009.

WOODWARD, B. Obama's War. New York: Simon \& Schuster, 2010. 